\title{
SPIEDw: a searchable platform-independent expression database web tool
}

\author{
Gareth Williams
}

\begin{abstract}
Background: SPIEDW is a web tool designed to facilitate fast and simple quantitative querying of publically available gene expression data. The resource is motivated by the observation that transcriptional profiles can serve as effective means of comparing biological states across a wide set of experiments.

Results: Gene expression data for over 200,000 experiments across multiple species and platforms have been collected into a searchable database. The new resource is a development of the previously published SPIED, which was designed to be downloaded and queried locally with SPIED software. SPIEDw features three significant improvements over the original version. Firstly, the number of experiments covered has been doubled and now includes Agilent and Illumina technologies. Secondly, SPIEDw has an enhanced search algorithm for speedy web-based querying and lastly an abridged dataset comprising the most regulated genes has been included for a speedier search and searching for enrichment of gene sets.
\end{abstract}

Conclusions: SPIEDW is simple to use, not requiring any expertise in microarray analysis, and the output straightforward to interpret. It is hoped that this will open up gene expression data mining to the wider research community.

Keywords: Global gene expression, Connectivity map, Microarray, EGF receptor, Parkinson's disease

\section{Background}

Gene expression data provides the most extensive quantitative insight into biological processes with close to a million separate data sets available [1,2]. The data is usually analysed from a gene centric point of view, with the objective of pinpointing a few perturbed genes that are subsequently independently validated. Alternatively, expression profiles can be viewed as the regulation of predefined gene sets representing canonical pathways [3] and ontology classes [4,5]. Various web tools allow for the navigation of deposited expression data. BioGPS [6] and SOURCE [7] are tools for gene comparison based on correlating expression profiles over large datasets. ArrayExpress Gene Expression Atlas [8] has compiled a database of significantly changing genes across nearly 100,000 expression samples and the user can search for expression series where a query gene or gene set are regulated. However, the observation that similar biological processes often exhibit correlated gene expression changes has

Correspondence: gareth.2.williams@kcl.ac.uk

Wolfson Centre for Age-Related Diseases, King's College London, London Bridge, London SE1 1UL, UK opened up the possibility of using expression databases to compare and contrast these processes [9,10]. In particular, the connectivity map (CMAP) has made available expression data for over a thousand drug treatments of human cell lines with the objective of mapping drug to disease through direct expression profile correlation [11]. This methodology has been extended to collections of published expression studies in GEM-TREND [12], ProfileChaser [13], Gene Expression Atlas [8] and SPIED [14]. The motivation behind SPIED was in the first place to define expression changes as relative to the average across the experimental series and thereby facilitate automatic curation and secondly to map expression changes to a uniquely defined set of genes thus allowing for the database to combine data from multiple platforms. The original version of SPIED has to be downloaded and searches performed locally with SPIED software. Here we present a web tool version of SPIED (SPIEDw). SPIEDw features a speedier search algorithm enabling 'real-time' web-based searching and consists of a greatly extended set of samples covering human, mouse and rat species from Illumina, Agilent and Affymetrix platform technologies, comprising 
half the available data for these species. In addition to exhaustive querying of global gene expression changes, a speedier search can be made of an abridged database comprising the most regulated genes. This latter functionality can also be deployed for gene set enrichment analysis.

\section{Results}

SPIEDw is hosted at www.spied.org.uk. Query expression profiles consist of text files with the first two columns corresponding to genes and their respective expression values. Gene names are according to the HGNC (HUGO Gene Nomenclature Committee) human gene nomenclature, see www.genenames.org. Given that the overwhelming majority of gene names are identical across human, mouse and rat queries can be constructed directly from rodent array data files. Queries should not contain multiple instances of genes. When a query is input containing multiple instances of a given gene only the first instance is retained in the query. Therefore, if the query is ranked according to significance only the most significant instances will form the query. Expression values can be defined in a number of ways, but treat up and down regulation symmetrically. Possible definitions are: $\begin{array}{cc}+1 & t>c \\ -1 & t<c\end{array}, \log \left(\frac{t}{c}\right), \frac{t-c}{t+c}$, where $t$ is the treatment and $c$ the control values. The database can either be queried exhaustively against the global gene changes or against subsets of top up and down regulated genes. Querying the latter database has the advantage of being much faster and unlike the global gene expression database it can be meaningfully queried with gene lists alone where it is of interest to look for enrichment for up or down regulation across experiments in SPIEDw. Searches can be restricted to a particular species (Human, Rodent, Mouse, Rat) or performed against the CMAP drug dataset. The output is in the form of a list of series names, sample names and corresponding scores. The output lists the top scoring samples and only one sample per series. The series and sample entries link to the relevant NCBI GEO (www.ncbi.nlm.nih.gov/geo/) pages giving full descriptions of the experimental set up. To see how the query scores against the whole series, from which a high scoring sample originates, there is a 'magnifying glass' button link against each output sample. The query scores against each sample in the series are ordered according to correlation score and the associated descriptors are shown. This is a simple way to see a possible correspondence between the biology underlying the series and that of the query. For clarity, the SPIEDw web

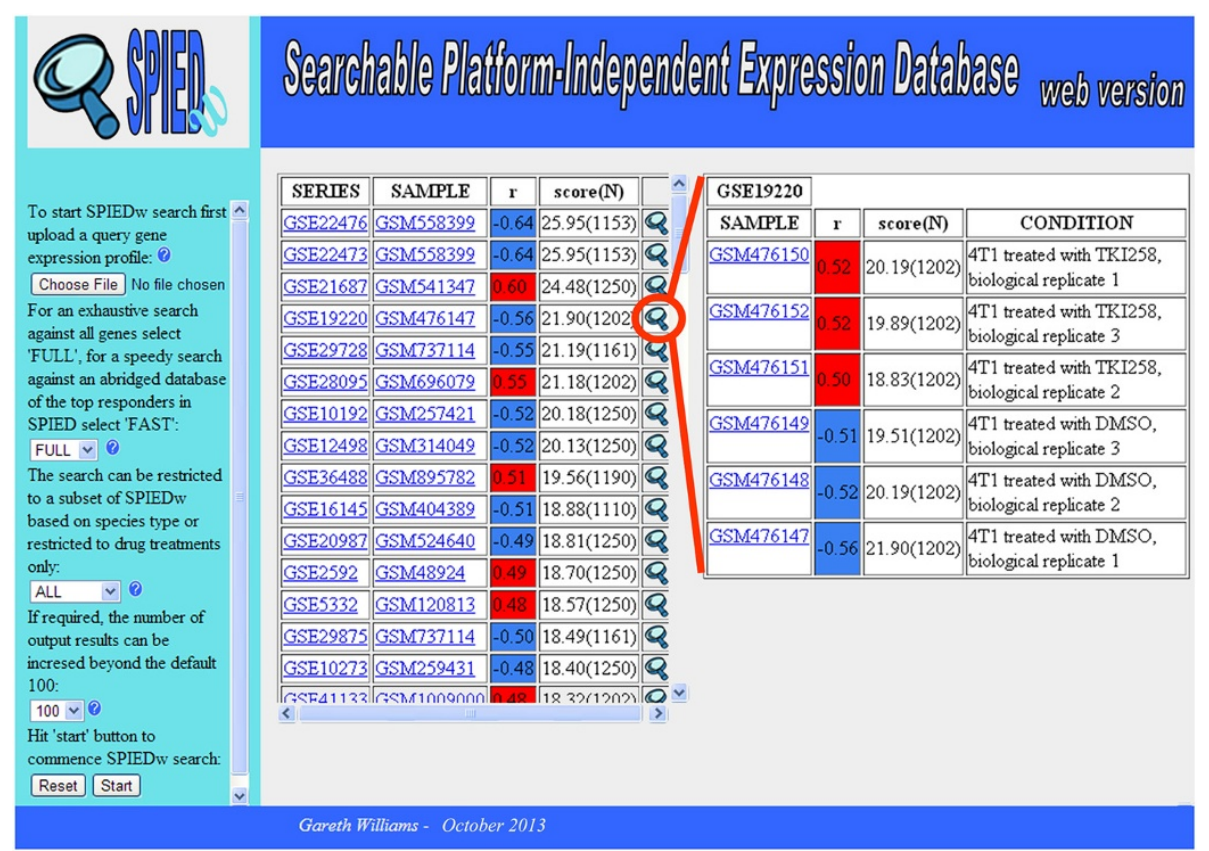

Figure 1 A SPIEDw worked example. The SPIEDw web page screen shot showing the various controls in the left column. A gene expression profile is uploaded, the user chooses whether to perform an exhaustive search or search only an abridged dataset comprising the most regulated genes. The latter is the appropriate option for performing gene list enrichment queries. Searches can be restricted to specific species and the number of top scoring samples returned can be increased beyond the default 100. We have performed a full search of SPIEDw with a profile corresponding to EGFR blockage in mouse neural stem cells [15]. The results column at the left lists the series id and sample id together with the correlation score and significance. The 'magnifying glass' button enables the user to see how the query scores against all the samples in the given series, displayed in the results column on the right. For example, the EGFR antagonism profile scores highly against a study of PI3K/AKT inhibition in mouse mammary carcinoma cells [16], and as expected, this correlation is positive with the inhibitor treated samples and negative with the control samples. 
interface is shown in Figure 1 together with a worked example. With the current server configuration full searches take just over four minutes.

Examples of the use of SPIED in diverse disease contexts were presented in some detail in the original publication [14]. However, for completeness we present an example where SPIEDw can be used to validate transcriptional signatures from Parkinson's (PD) disease and shed light on animal models of PD. This complements the analysis of Alzheimer's disease (AD) presented in [14]. The notorious difficulty of obtaining good quality RNA from post-mortem brain samples $[17,18]$ raises legitimate concerns over the robustness of neurodegenerative disease associated transcription signatures. However, when there is a significant correlation with independently derived disease profiles in the public domain we can be more confident that these profiles describe the disease. SPIEDw offers a straightforward application here. To this end we took a PD signature form a multi-regional brain expression study [19]. By combining the gene change profiles form the three regions we defined a profile of 235 genes (67 up and 168 down, see Additional file 1 for details). When this profile is queried against the human subset of SPIEDw we find nine independent PD profiles in the top 100 experimental series, see Table 1 . Thus these results go some way towards validating the profile. Profiles from other neurodegenerative conditions also score highly, see Table 2. Because the given expression series consists of samples from multiple brain areas with corresponding controls, a better idea of the disease correlation can be seen between statistically filtered expression profiles based on grouping control and disease sets. Example regression plots are shown in Figure 2A and B and it is clear that there is a substantial overlap between the PD query and two independent PD profiles. This correlation is also seen

Table 1 The PD query profile scores highly against nine other PD expression studies, thus validating the query as a disease signature

\begin{tabular}{llll}
\hline & & \multicolumn{2}{c}{ Parkinson's disease } \\
\hline Rank & Series & $\mathbf{r}$ & Description \\
\hline 1 & GSE8397 & -0.92 & Parkinsonian Brain \\
13 & GSE20168 & -0.88 & Prefrontal area 9 in Parkinson's disease \\
& GSE7621 & -0.82 & $\begin{array}{l}\text { Substantia nigra from postmortem human } \\
\text { brain of Parkinson's disease }\end{array}$ \\
58 & GSE28894 & -0.78 & $\begin{array}{l}\text { Multiple regions of the Parkinson's } \\
\text { disease brain }\end{array}$ \\
71 & GSE20141 & -0.62 & Laser-dissected SNpc neurons in \\
89 & GSE20292 & -0.55 & Substantia nigra in Parkinson's disease \\
97 & GSE19587 & -0.53 & Parkinson's disease \\
99 & GSE20291 & -0.51 & Putamen in Parkinson's disease \\
\hline
\end{tabular}

Table 2 Parkinson's disease query correlates with the expression profiles of multiple neurodegenerative expression

\begin{tabular}{|c|c|c|c|}
\hline \multicolumn{4}{|c|}{ Frontal temporal lobe dementia } \\
\hline Rank & Series & $r$ & Description \\
\hline 2 & GSE13162 & 0.92 & Samples with and without FTLD-U \\
\hline \multicolumn{4}{|c|}{ Huntington's disease } \\
\hline Rank & Series & $r$ & Description \\
\hline 5 & GSE3790 & 0.84 & $\begin{array}{l}\text { Cerebellum, frontal cortex and caudate } \\
\text { nucleus HD tissue }\end{array}$ \\
\hline \multicolumn{4}{|c|}{ Down's syndrome } \\
\hline Rank & Series & $r$ & Description \\
\hline 7 & GSE5390 & 0.84 & $\begin{array}{l}\text { Down syndrome and healthy control } \\
\text { subjects }\end{array}$ \\
\hline 86 & GSE1397 & 0.55 & Trisomy 21 and TS13 \\
\hline \multicolumn{4}{|c|}{ Bipolar disorder } \\
\hline Rank & Series & $r$ & Description \\
\hline 10 & GSE5388 & 0.83 & $\begin{array}{l}\text { Adult dorsolateral prefrontal cortex: bipolar } \\
\text { disorder and healthy controls }\end{array}$ \\
\hline 11 & GSE5389 & 0.83 & $\begin{array}{l}\text { Adult orbitofrontal cortex: bipolar disorder } \\
\text { and healthy controls }\end{array}$ \\
\hline 15 & GSE5392 & 0.82 & $\begin{array}{l}\text { Adult brain tissue from subjects with bipolar } \\
\text { disorder and healthy controls }\end{array}$ \\
\hline
\end{tabular}

Alzheimer's disease

$\begin{array}{llll}\text { Rank } & \text { Series } & \mathbf{r} & \text { Description } \\ 14 & \text { GSE16759 } & -0.82 & \text { Parietal lobe cortex in Alzheimer's disease } \\ 26 & \text { GSE1297 } & -0.75 & \text { Incipient Alzheimer's Disease } \\ 38 & \text { GSE5281 } & 0.69 & \begin{array}{l}\text { Alzheimer's disease and the normal } \\ \text { aged brain }\end{array} \\ 56 & \text { GSE12685 } & -0.63 & \text { Incipient AD } \\ 68 & \text { GSE4757 } & 0.61 & \text { Alzheimer's disease neurofibrillary tangles }\end{array}$

Nasu-Hakola disease

Rank Series $r \quad$ Description

33 GSE25496 0.73 Nasu-Hakola disease brain

Multiple sclerosis

$\begin{array}{llll}\text { Rank } & \text { Series } & \mathbf{r} & \text { Description } \\ 40 & \text { GSE5839 } & 0.69 & \begin{array}{l}\text { Multiple Sclerosis Brain tissue in comparison } \\ \text { to control brain tissue }\end{array}\end{array}$

Amyotropic lateral sclerosis

$\begin{array}{llll}\text { Rank } & \text { Series } & \mathbf{r} & \text { Description } \\ 54 & \text { GSE4595 } & -0.66 & \begin{array}{l}\text { Motor cortex in sporadic amyotrophic } \\ \text { lateral sclerosis }\end{array} \\ & & & \end{array}$

with profiles corresponding to $\mathrm{AD}$ and Huntington's diseases (HD), see Table 3 and the two regression plots in Figure $2 \mathrm{C}$ and $\mathrm{D}$. When the PD profile is queried against the rodent subset of SPIEDw we find that there is a significant correlation with rodent models of neurodegeneration, see Table 4, and in particular a mouse model of PD based on the administration of MPTP (GEO accession GSE7707). This is in contrast to the AD 

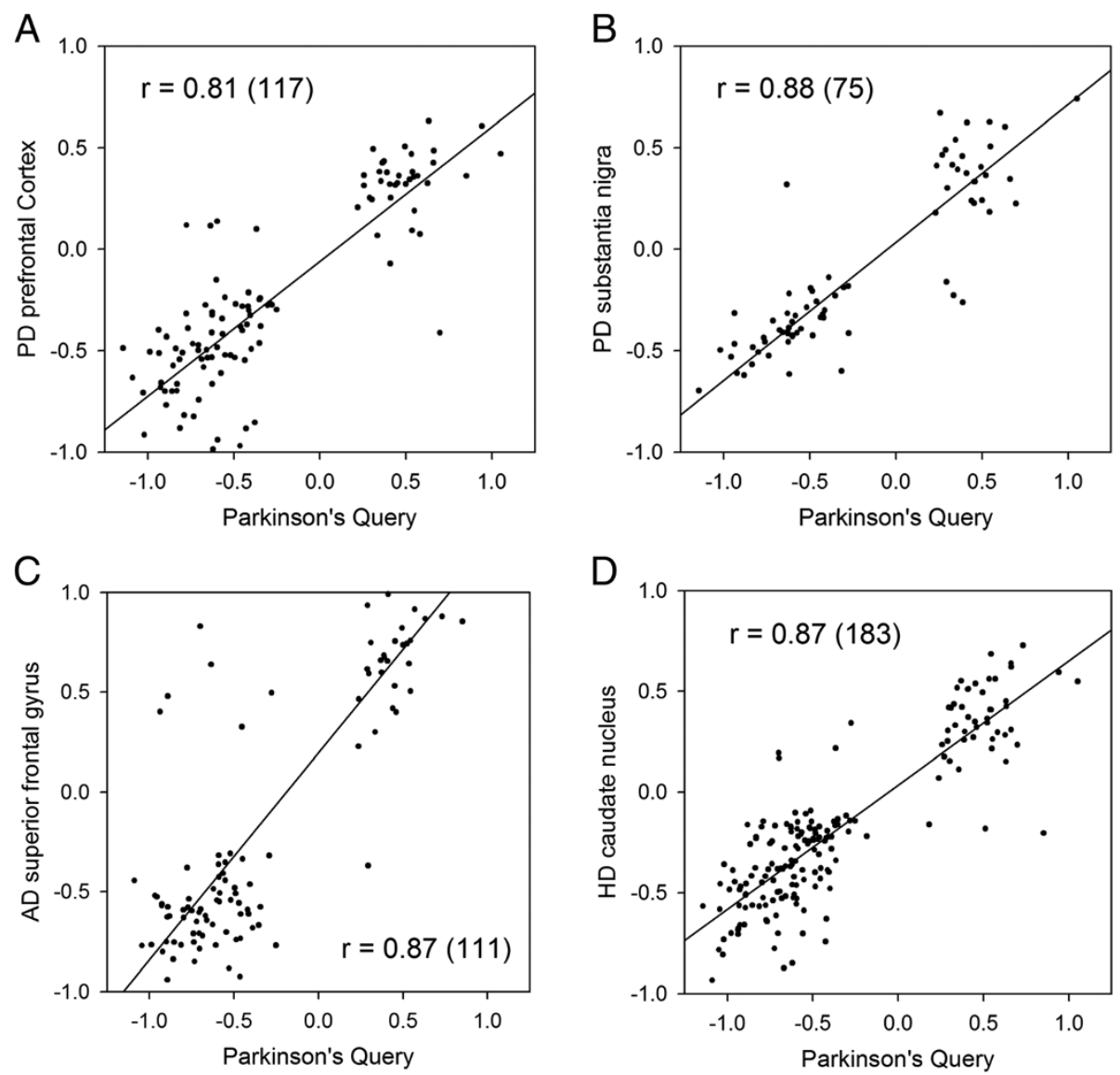

Figure 2 The regression plots for the PD query profile against high scoring PD, AD and HD expression studies in SPIEDw. The regression plots are shown for high scoring PD expression profiles derived from post-mortem brain samples from two independent publications. In $\mathbf{A}$ the PD query is plotted against a PD profile from the prefrontal cortex [20] and in $\mathbf{B}$ against a PD profile from the substantia nigra [21]. The PD query also scores highly against other neurodegenaration disease profiles and two example regression plots are shown in $\mathbf{C}$, for an AD profile from the superior frontal gyrus [22], and $\mathbf{D}$, a HD profile from the caudate nucleus [23].

situation, where there doesn't appear to be any significant correlation with animal models of the disease (GW unpublished observation). Again to get a better idea of the overlap of the query profile with the rodent model profiles we generated statistically filtered profiles for the various conditions and generated regression scores. These are shown in Table 4. Interestingly, the PD correlation with the MPTP model only holds up in the striatum as opposed to the midbrain or frontal cortex. Also, a significant correlation emerges with late stage profiles of the spinal chord injury model and the SOD1(G93A) model of Amyotropic lateral sclerosis (ALS) (GEO accession GSE18597), a similar result to previously published AD query results [14]. The expression profiles used in the regression analyses together with the PD query profile are given in the Additional file 1.

\section{Discussion and conclusions}

The motivation behind SPIEDw is to facilitate the simple quantitative comparison of biological states through their underlying gene transcription profiles. In comparison to the previously published SPIED, the new database has three notable improvements. Firstly, an enhanced search algorithm has enabled queries to be performed in 'real time' on the web. Secondly, the number of expression samples comprising the database has been doubled, now covering Illumina and Agilent as well as Affymetrix platform technologies. Lastly, an abridged dataset comprising the most regulated genes has been included for a speedier search and for gene set enrichment analysis. The tool is simple to use, with queries consisting only of gene names and expression changes. The output is straightforward to interpret, giving direct links to the deposited data for the high scoring SPIEDw entries. It is hoped that this will open up gene expression data mining to the wider research community. At present SPIEDw consists of human and rodent arrays, where there is a great deal of homology and mostly unambiguous gene assignment. However, there have been extensive gene expression studies in more distant species, 
Table 3 The PD query correlates with the expression profiles of rodent models of neurodegeneration

\begin{tabular}{|c|c|c|c|}
\hline \multicolumn{4}{|c|}{ Amyotrophic lateral sclerosis (ALS) model } \\
\hline Rank & Series & $r$ & Description \\
\hline 12 & GSE18597 & 0.6 & Mutant SOD1(G93A) transgenic mice \\
\hline \multicolumn{4}{|c|}{ Ischemia } \\
\hline Rank & Series & $r$ & Description \\
\hline 44 & GSE23163 & 0.56 & $\begin{array}{l}\text { Ischemic/reperfusion injury in an in vivo } \\
\text { mouse model }\end{array}$ \\
\hline 49 & GSE23162 & 0.55 & $\begin{array}{l}\text { Ischemic/reperfusion injury in an in vivo } \\
\text { Gpx } 1-/- \text { transgenic mouse model }\end{array}$ \\
\hline 92 & GSE28201 & 0.44 & Ischemic Mouse Brain Transcriptome \\
\hline 93 & GSE33725 & 0.44 & $\begin{array}{l}\text { Effect of erythropoietin on cerebral ischemia } \\
\text { in rat }\end{array}$ \\
\hline \multicolumn{4}{|c|}{ Parkinson's model } \\
\hline Rank & Series & $r$ & Description \\
\hline 55 & GSE7707 & -0.49 & Mouse MPTP model of Parkinson's disease \\
\hline \multicolumn{4}{|c|}{ Spinal chord injury } \\
\hline Rank & Series & $\mathbf{r}$ & Description \\
\hline 98 & GSE5296 & 0.42 & Spinal Cord Injury Murine Model \\
\hline \multicolumn{4}{|l|}{ Other } \\
\hline Rank & Series & $r$ & Description \\
\hline 13 & GSE18356 & -0.61 & $\begin{array}{l}\text { Rat model of neonatal HI encephalopathy }+/- \\
\text { antioxidant }\end{array}$ \\
\hline 19 & GSE24131 & 0.58 & Hypoxia effect on mouse neural stem cells \\
\hline 41 & GSE14802 & 0.52 & $\begin{array}{l}\text { Smith-Magenis and Potocki-Lupski syndrome } \\
\text { mouse model }\end{array}$ \\
\hline 54 & GSE30577 & -0.49 & $\begin{array}{l}\text { Brain and Spinal cord following Lethal } \\
\text { CVS-11 Infection in Mice }\end{array}$ \\
\hline 87 & GSE25250 & -0.44 & $\begin{array}{l}\text { Cerebellum from mice exposed to chronic } \\
\text { low-level chlorpyrifos oxon }\end{array}$ \\
\hline 88 & GSE12196 & 0.53 & Rat exposure to RDX \\
\hline
\end{tabular}

Table 4 The regression scores for the PD query profile against mouse models of neurodegeneration

\begin{tabular}{lcc}
\hline \multicolumn{2}{c}{ MPTP mouse PD model } & $\mathbf{N}$ \\
\hline Brain region & $\mathbf{r}$ & 56 \\
\hline Striatum & 0.39 & 32 \\
Midbrain & 0.08 & 31 \\
Frontal cortex & -0.19 & \\
SOD1 (G93A) mouse ALS model & & $\mathbf{N}$ \\
stage (days) & $\mathbf{r}$ & 63 \\
$\quad$ 28-40 & 0.21 & 104 \\
$\quad 112-126$ & 0.48 & \\
Mouse spinal chord injury & & $\mathbf{N}$ \\
stage & $\mathbf{r}$ & 57 \\
\multicolumn{1}{c}{ 24 h } & 0.33 & 65 \\
\hline
\end{tabular}

such as drosophila. It is hoped to extend SPIEDw in this direction with appropriate gene lists.

\section{Methods}

Gene expression sample files were downloaded from NCBI GEO (www.ncbi.nlm.nih.gov/geo/) covering human, mouse and rat species on multiple platforms based on Affymetrix, Illumina and Agilent technologies. In particular the platforms are: Affymetrix \{GPL570, GPL96, GPL 6244, GPL571, GPL1261, GPL81, GPL6246, GPL85, GPL1 355\}; Illumina \{GPL6947, GPL6104, GPL6883, GPL6102, GPL10558, GPL6884, GPL6887, GPL6885, GPL6105\}; Agi lent \{GPL4133, GPL6480, GPL1708, GPL4134, GPL7202, GPL4135, GPL7294, GPL2877, GPL890\}. As in the original version of SPIED, the array probe sets are mapped onto HGNC human genes. Each sample entry of SPIEDw consists of a list of genes ranked according to relative expression level in the given series to which the sample belongs. In addition an abridged database with individual sample entries corresponding to the top 500 most up/ down regulated genes has been generated for fast querying. Here the top $500 \mathrm{up} /$ down regulated genes are assigned only up/down status and query correlations are based on a Fisher exact test, see below. This database can also be queried for gene set enrichment analysis. Drug treatment data was downloaded from the Broad connectivity map site and here multiple drug instances were combined to obtain average response profiles and the SPIEDw entries for these consist of the ranked list of significantly affected genes $(p<0.05$ by Student's $t$-test) according to fold magnitude.

For full and drugs set searches query profiles are scored according to the significance of the Pearson's correlation. In particular the ranking score is $s=\frac{\sqrt{N-3}}{2}\left|\operatorname{In}\left(\frac{1+r}{1-r}\right)\right|$, where $r$ is the Pearson's correlation coefficient and $N$ is the number of genes in the given correlation. To enable the user to make an assessment of the significance of the output, $r$, $s$ and $N$ are provided for each sample. The abridged database search is based on a Fisher exact test, where the given distribution of query genes in each database entry is compared to a random distribution and scored accordingly. Here, the separate enrichment scores for the up and down regulated genes are combined for the ranking score. Therefore a meaningful significance score will result from queries without fold change information. That is, the abridged database search can be used to look for enrichment of gene sets. In this case the query consists of a gene list with folds set to unity, see Additional file 2 for details.

To speed up database querying the data has been compressed into a base 150 format. Here the overwhelming majority of gene numbers are represented by no more than two indices, corresponding to ASCII characters. This results in a compression ratio of $59 \%$. Data is read 
in blocks of 1000 arrays and processed. Note that converting the read buffers to integers is as fast for the base 150 data as for the uncompressed data.

\section{Availability of SPIED}

SPIEDw is available at www.spied.org.uk. Current version is 2.0 and new builds will become available in due course, incorporating more recent expression data.

\section{Additional files}

\section{Additional file 1: Expression profile details for queries used in Results analysis together with corresponding correlating profiles from SPIEDw. Excel spread sheet. with gene names, fold changes and p-values for transcripts with significantly altered expression levels for the example PD query and correlating profiles from PD, AD, HD human samples. Correlating profiles form a mouse MPTP model of PD together with a mouse SOD1(G93A) model of ALS and a mouse model of spinal chord injury are also given.}

Additional file 2: Example of SPIEDw with gene set query. A worked example with a query consisting of a gene set. Querying the abridged database ('FAST' mode query) enables the user to discover SPIEDW response profiles with significantly enriched query gene sets.

\section{Competing interests}

The author declare that he has no competing interests.

\section{Authors' contributions}

GW is the sole author of the present study.

\section{Acknowledgements}

This work was supported by the Wolfson CARD. I would like to thank Ramin Raouf for help in setting up the web tool.

Received: 28 January 2013 Accepted: 28 October 2013

Published: 7 November 2013

\section{References}

1. Barrett $T$, Troup DB, Wilhite SE, Ledoux P, Rudnev D, Evangelista C, Kim IF, Soboleva A, Tomashevsky M, Edgar R: NCBI GEO: mining tens of millions of expression profiles-database and tools update. Nucleic Acids Res 2007 35(Database issue):D760-D765.

2. Parkinson $\mathrm{H}$, Sarkans U, Kolesnikov N, Abeygunawardena N, Burdett T, Dylag M, Emam I, Farne A, Hastings E, Holloway E, et al: ArrayExpress update-an archive of microarray and high-throughput sequencingbased functional genomics experiments. Nucleic Acids Res 2011, 39(Database issue):D1002-D1004.

3. Subramanian A, Tamayo P, Mootha VK, Mukherjee S, Ebert BL, Gillette MA, Paulovich A, Pomeroy SL, Golub TR, Lander ES, et al: Gene set enrichment analysis: a knowledge-based approach for interpreting genome-wide expression profiles. Proc Natl Acad Sci USA 2005, 102(43):15545-15550.

4. Zeeberg BR, Feng W, Wang G, Wang MD, Fojo AT, Sunshine M, Narasimhan S, Kane DW, Reinhold WC, Lababidi S, et al: GoMiner: a resource for biological interpretation of genomic and proteomic data. Genome Bio/ 2003, 4(4):R28.

5. Ashburner M, Ball CA, Blake JA, Botstein D, Butler H, Cherry JM, Davis AP, Dolinski K, Dwight SS, Eppig JT, et al: Gene ontology: tool for the unification of biology. The gene ontology consortium. Nat Genet 2000 25(1):25-29

6. Wu C, Orozco C, Boyer J, Leglise M, Goodale J, Batalov S, Hodge CL, Haase J, Janes J, Huss JW 3rd, et al: BioGPS: an extensible and customizable portal for querying and organizing gene annotation resources. Genome Biol 2009, 10(11):R130.

7. Diehn M, Sherlock G, Binkley G, Jin H, Matese JC, Hernandez-Boussard T, Rees CA, Cherry JM, Botstein D, Brown PO, et al: SOURCE: a unified genomic resource of functional annotations, ontologies, and gene expression data. Nucleic Acids Res 2003, 31(1):219-223.
8. Kapushesky M, Adamusiak T, Burdett T, Culhane A, Farne A, Filippov A, Holloway E, Klebanov A, Kryvych N, Kurbatova N, et al: Gene expression atlas update-a value-added database of microarray and sequencing-based functional genomics experiments. Nucleic Acids Res 2012, 40(Database issue):D1077-D1081.

9. Marton MJ, DeRisi JL, Bennett HA, lyer VR, Meyer MR, Roberts CJ, Stoughton R, Burchard J, Slade D, Dai H, et al: Drug target validation and identification of secondary drug target effects using DNA microarrays. Nat Med 1998, 4(11):1293-1301.

10. Hughes TR, Marton MJ, Jones AR, Roberts CJ, Stoughton R, Armour CD, Bennett HA, Coffey E, Dai H, He YD, et al: Functional discovery via a compendium of expression profiles. Cell 2000, 102(1):109-126.

11. Lamb J, Crawford ED, Peck D, Modell JW, Blat IC, Wrobel MJ, Lerner J, Brunet JP, Subramanian A, Ross KN, et al: The connectivity Map: using gene-expression signatures to connect small molecules, genes, and disease. Science 2006, 313(5795):1929-1935.

12. Feng $C$, Araki M, Kunimoto $R$, Tamon A, Makiguchi $H$, Niijima $S$, Tsujimoto G, Okuno Y: GEM-TREND: a web tool for gene expression data mining toward relevant network discovery. BMC Genomics 2009, 10:411.

13. Engreitz JM, Chen R, Morgan AA, Dudley JT, Mallelwar R, Butte AJ: ProfileChaser: searching microarray repositories based on genome-wide patterns of differential expression. Bioinformatics 2011, 27(23):3317-3318.

14. Williams G: A searchable cross-platform gene expression database reveals connections between drug treatments and disease. BMC Genomics 2012, 13:12

15. Sutterlin P, Williams EJ, Chambers D, Saraf K, von Schack D, Reisenberg M, Doherty $P$, Williams G: The molecular basis of the cooperation between EGF, FGF and eCB receptors in the regulation of neural stem cell function. Mol Cell Neurosci 2013, 52:20-30.

16. Dey JH, Bianchi F, Voshol J, Bonenfant D, Oakeley EJ, Hynes NE: Targeting fibroblast growth factor receptors blocks PI3K/AKT signaling, induces apoptosis, and impairs mammary tumor outgrowth and metastasis. Cancer Res 2010, 70(10):4151-4162.

17. Barton AJ, Pearson RC, Najlerahim A, Harrison PJ: Pre- and postmortem influences on brain RNA. J Neurochem 1993, 61(1):1-11.

18. Webster MJ: Tissue preparation and banking. Prog Brain Res 2006, 158:3-14

19. Moran LB, Duke DC, Deprez M, Dexter DT, Pearce RK, Graeber MB: Whole genome expression profiling of the medial and lateral substantia nigra in Parkinson's disease. Neurogenetics 2006, 7(1):1-11.

20. Zhang Y, James M, Middleton FA, Davis RL: Transcriptional analysis of multiple brain regions in Parkinson's disease supports the involvement of specific protein processing, energy metabolism, and signaling pathways, and suggests novel disease mechanisms. Am J Med Genet B Neuropsychiatr Genet 2005, 137B(1):5-16.

21. Lesnick TG, Papapetropoulos S, Mash DC, Ffrench-Mullen J, Shehadeh L, de Andrade M, Henley JR, Rocca WA, Ahlskog JE, Maraganore DM: A genomic pathway approach to a complex disease: axon guidance and Parkinson disease. PLoS Genet 2007, 3(6):e98.

22. Liang WS, Dunckley T, Beach TG, Grover A, Mastroeni D, Walker DG, Caselli RJ, Kukull WA, McKeel D, Morris JC, et al: Gene expression profiles in anatomically and functionally distinct regions of the normal aged human brain. Physio/ Genomics 2007, 28(3):311-322.

23. Hodges A, Strand AD, Aragaki AK, Kuhn A, Sengstag T, Hughes G, Elliston LA, Hartog C, Goldstein DR, Thu D, et al: Regional and cellular gene expression changes in human Huntington's disease brain. Hum Mol Genet 2006, 15(6):965-977.

doi:10.1186/1471-2164-14-765

Cite this article as: Williams: SPIEDw: a searchable platform-independent expression database web tool. BMC Genomics 2013 14:765. 